\title{
NEURONAL DAMAGE IN BRAINS OF FIRST- AND SECOND-GENERATION PUPS BORN TO HYPOTHYROID WISTAR RATS
}

\author{
Mariyah Hidayat ${ }^{1 \otimes}$, Yasmeen Mahar ${ }^{2}$, Khalid Pervez Lone ${ }^{3}$
}

\begin{abstract}
OBJECTIVE: To study neuronal damage in brains of first and second-generation pups, born to hypothyroid Wistar rats.

METHODS: Ten female adult Wistar rats, randomized into two equal groupspropylthiouracil (Group-P) and control (Group-C) were allowed to conceive. Group-P was given oral propylthiouracil throughout gestational period and weaning until $22^{\text {nd }}$ day. Nine offspring from group-C (C/FC) and group-P (P/FC) were sacrificed on $22^{\text {nd }}$ day of life to collect blood and brain samples. The dams of group-P (group-PP) were allowed to conceive and continued with propylthiouracil treatment throughout gestation and weaning. Their nine offsprings (PP/FC) were sacrificed on $22^{\text {nd }}$ day. Serum levels of triiodothyronine $\left(T_{3}\right)$, thyroxine $\left(T_{4}\right)$ and thyroid stimulating hormone $(T S H)$ were measured. Brain weight, apoptotic cell count (ACC) of Purkinje cells of cerebellar cortex and Pyramidal cells of hippocampus were documented.
\end{abstract}

RESULTS: Mean TSH levels were $2 \mathrm{I} \pm 3 \mathrm{ng} / \mathrm{dl}, 23.3 \pm 3.5 \mathrm{ng} / \mathrm{dl}$ and $10 \pm 2.1 \mathrm{ng} / \mathrm{dl}$ in $P / F C, P P / F C$ and $C / F C$ respectively $(p=0.003)$. Mean $T_{4}$ was $31.7 \pm 1.2 n g / d l$, $30.3 \pm 1.3 \eta \mathrm{g} / \mathrm{dl}$ and $36.3 \pm 0.9 \eta \mathrm{g} / \mathrm{dl}$ in $\mathrm{P} / \mathrm{FC}, \mathrm{PP} / \mathrm{FC}$ and $\mathrm{C} / \mathrm{FC}$ respectively $(p=0.030)$. Mean brain weights was $1.21 \pm 0.21 \mathrm{mg}, 1.20 \pm 0.41 \mathrm{mg}$ and I.42 \pm 0.01 mg group in P/FC, PP/FC and C/FC respectively $(p>0.05)$. The normal Pyramidal and Purkinje cell count was low in P/FC and PP/FC groups compared to $C / F C$ group $(p<0.05)$. The ACC of Pyramidal and Purkinje cells was high in P/FC and PP/FC groups compared to C/FC group $(p<0.05)$.

CONCLUSION: Maternal hypothyroidism adversely affected the morphology of Pyramidal and Purkinje cells by enhancing apoptosis, which increased further in second generation pups.

KEY WORDS: Thyroid Hormones (MeSH); Hypothyroidism (MeSH); Neurons (MeSH); Pregnancy (MeSH); Apoptosis (MeSH); Rats, Wistar (MeSH); Triiodothyronine (MeSH); Thyroxine (MeSH); Purkinje Cells (MeSH); Pyramidal Cells $(\mathrm{MeSH})$.

THIS ARTICLE MAY BE CITED AS: Hidayat M, Mahar Y, Lone KP. Neuronal damage in brains of first- and second-generation pups born to hypothyroid Wistar rats. Khyber Med Univ J 2020;12(3):197-203. DOI: 10.35845/kmuj.2020.20183.

\section{INTRODUCTION}

To he thyroid gland synthesizes hormones named thyroxine $\left(T_{4}\right)$ and triiodothyronine $\left(T_{3}\right)$, which regulate growth and functions of almost all the vital organs and structures.' Various experimental studies have unanimously proved that the main organ of the body directly targeted by thyroid hormones (THs) is the brain. ${ }^{2,3}$ These hormones are indispensable for the development and functioning of the brain throughout life. ${ }^{4}$ Disturbances in the functions of the thyroid gland are one of the most commonly encountered endocrine disorders. ${ }^{2}$ Hypothyroidism is the prevailing form of thyroid disease and it is manifested in the form of memory and learning impairment, depression, psychosis, slow motor activity, sleepiness, decline in intellectual ability and rarely coma. ${ }^{5,6}$ Since the thyroid hormones greatly affect the maturation of neurons concerned with learning and memory
I. Department Anatomy, University of Health Sciences, Lahore, Pakistan.

2. Department of Anatomy, Bahria University Medical and Dental College, Karachi, Pakistan.

3. Department of Physiology and Cell Biology, University of Health Sciences, Lahore, Pakistan.

Email|: drmariyah.hidayat@gmail.com Contact \# : +92-300-2588375

$\begin{array}{ll}\text { Date Submitted: } & \text { March 03, } 2020 \\ \text { Date Revised: } & \text { August 22, } 2020 \\ \text { Date Accepted: } & \text { August 24, } 2020\end{array}$

e.g., the neurons located in hippocampus and frontal cortex, the deficiency of these hormones during the neuronal maturation causes mental retardation, which may be permanent. ${ }^{5,6}$

During development of brain, THs act by binding to nuclear receptors dispersed extensively in the fetal brain which are present even before the fetal ability to synthesize them. ${ }^{7}$ In humans, THs deficiency during brain development can lead to alterations in the structure and functions of cerebral cortex, hippocampus and cerebellar cortex. ${ }^{4,8-10}$ If hypothyroidism manifests during fetal and neonatal period, it hinders the process of differentiation and connectivity of neurons." Usually THs deficiency during fetal or early postnatal life results in brain damage. ${ }^{2}$ which may be due to abnormal neuronal proliferation and migration. ${ }^{12}$ In humans, THs deficiency during the first four weeks after birth leads to cretinism, which manifests as mental retardation and neurological insufficiencies. ${ }^{13}$

Lack of THs leads to extensive apoptosis during neurogenesis. ${ }^{14}$ Even subclinical hypothyroidism during early pregnancy can be deleterious to the development of fetal brain. ${ }^{15}$ Both the magnitude and the duration of apoptosis is increased in congenital hypothyroidism by suppression of the anti-apoptotic gene $\mathrm{Bcl}-2$ and 
TABLE I: MEAN SERUM THYROID STIMULATING HORMONE (TSH), TRIIODOTHYRONINE $\left(T_{3}\right)$ AND THYROXINE $\left(T_{4}\right)$ LEVELS IN 22 DAYS OLD PUPS

\begin{tabular}{|c|c|c|c|}
\hline Groups $(n=9)$ & $\begin{array}{l}\text { TSH (ng/dL) } \\
(M e a n \pm S D)\end{array}$ & $\begin{array}{c}T_{3}(\eta g / d L) \\
(M e a n \pm S D)\end{array}$ & $\begin{array}{c}T_{4}(n g / d L) \\
(M e a n \pm S D)\end{array}$ \\
\hline $\mathrm{C} / \mathrm{FC}$ & $10 \pm 2.1$ & $39.7 \pm 0.5$ & $36.3 \pm 0.9$ \\
\hline $\mathrm{P} / \mathrm{FC}$ & $21 \pm 3.7$ & $39.3 \pm 0.4$ & $31.7 \pm 1.2$ \\
\hline $\mathrm{PP} / \mathrm{FC}$ & $23.3 \pm 3.5$ & $39.3 \pm 0.4$ & $30.3 \pm 1.3$ \\
\hline $\mathrm{R} 2$ & $68.18 \%$ & $27.49 \%$ & $50.86 \%$ \\
\hline$P$ value & 0.003 & 0.130 & 0.030 \\
\hline
\end{tabular}

upregulation of the pro-apoptotic gene Bax. ${ }^{16}$

Rat pups are born with a comparatively undeveloped brain. ${ }^{17}$ The effects of THs on the development of brain in the rat occur in the early neonatal period. The first 2-3 weeks of life is defined as the time period during which $\mathrm{THs}$ are required for normal brain development in rodents. ${ }^{17}$ This period generally parallels the last trimester in humans. In both humans and rodents, if the hormone replacement therapy is delayed, it will cause structural and functional impairment of neurons permanently.

There remains a gap in knowledge regarding the effect of low $\mathrm{TH}$ levels on functions of motor neurons. It has been documented that hypothyroidism causes impairment of brain functions, but its direct effects on the process of apoptosis involving motor neurons has not been defined. Considering the critical part played by $\mathrm{THs}$ on brain development, the current study investigates the outcome of hypothyroidism in the neonatal rat brains and how it leads to decline in motor functions.

\section{METHODS}

This experiment was conducted in the Department of Anatomy, University of Health Sciences, Lahore, from September to December of 2018. This study was approved by the Ethical Committee of University of Health Sciences, Lahore (UHS) and was conducted according to the guidelines for the sacrifice of experimental animals, as laid down in American Veterinary Medical Association (AVMA). ${ }^{18}$ After procuring 10 adult female Wistar albino rats from animal house, each animal was weighed and thoroughly evaluated by gross inspection. All the apparently healthy rats were of 12-16 weeks of age with a weight range of $190-210 \mathrm{~g}$. They were acclimatized in their allotted cages for one week before the commencement of the study. The rats were maintained in the animal house under controlled environment i.e. well-ventilated room at a temperature of $23 \pm 2^{\circ} \mathrm{C}$, humidity $55 \pm 5 \%$ and light and dark cycles of 12 hours each (light on at 8:00 and off at 20:00 hours). They were fed on standard rat diet and water ad libitum.

After a week of acclimatization, the treatment of both the groups was started one week before conception. The appearance of the vaginal plug was considered as the first day of pregnancy. As the period of gestation is around 2223 days in albino rats, and the experiment ended on $22^{\text {nd }}$ postnatal day in the $2^{\text {nd }}$ generation pups, the total time duration of this experiment was between $15-16$ weeks.

A week before mating, 10 adult female rats were divided into 2 equal groups. This division was carried out randomly and each rat was tail marked for identification. Five adult females, serving as control group $C$, consisted of dams in a euthyroid state. Propylthiouracil (PTU) was given orally in a dose of $15 \mathrm{mg} / \mathrm{kg} /$ day by mixing it in rat chow on daily basis to group $P$ rats. ${ }^{19}$ The treatment was continued throughout gestation and weaning. Nine offspring from both the groups were chosen for further study and sacrificed on $22^{\text {nd }}$ postnatal day, after receiving PTU indirectly throughout gestation and lactation. None of the mothers were sacrificed in this experiment.

The dams of $\mathrm{P}$ group were continued administration of PTU beyond $22^{\text {nd }}$ day, and once again allowed to conceive around $30^{\text {th }}$ day after delivery. This time they were renamed as PP group. The treatment was continued throughout next pregnancy till the end of $22^{\text {nd }}$ day postnatally. Nine offspring, labelled as PP/FC group, were sacrificed respectively on $22^{\text {nd }}$ postnatal day, after receiving PTU indirectly throughout gestation and lactation.

After euthanization, blood samples were immediately collected, from the cardiac region by inserting the needle under the sternum slightly to the left, to measure serum levels of $\mathrm{T}_{3}, \mathrm{~T}_{4}$ and TSH using rat specific enzyme linked immunosorbent assay (ELISA) kits manufactured by Elabscience $\AA$, Texas, USA, according to manufacturer instructions.

Now the scalp was retracted to reveal the skull and an incision made in the bone along the midline. The brains were then extracted from the skull with the help of a spatula and observed for any gross lesion. There was no significant morphological change seen in any of the brains of the pups belonging to both first and second generation.

For histological examination, brains were fixed in 10\% formalin, immediately after sacrifice, for 14-16 hours, dehydrated in ascending grades of alcohol, for I hour each and then cleared in xylene. Tissues were then embedded in paraffin wax $\left(56-58^{\circ} \mathrm{C}\right.$ melting point) and $3 \mu \mathrm{m}$ thick sections were processed further for immunehistochemical (IHC) staining, by using monoclonal anti-Bax antibody as the primary anti-body and Horseradish Peroxidase (HRP) as the secondary antibody. The slides were later counterstained with Hematoxylin and rinsed in tap water, dehydrated in ascending series of alcohol, cleared in xylene and mounted in DPX to be visualized under the light microscope. The parameters used to label the cells as apoptotic were size of the cell body, fragmentation of the nucleus, extent of Bax staining of the cell nucleus or cytoplasm. Neurons having a deeply stained cytoplasm and 


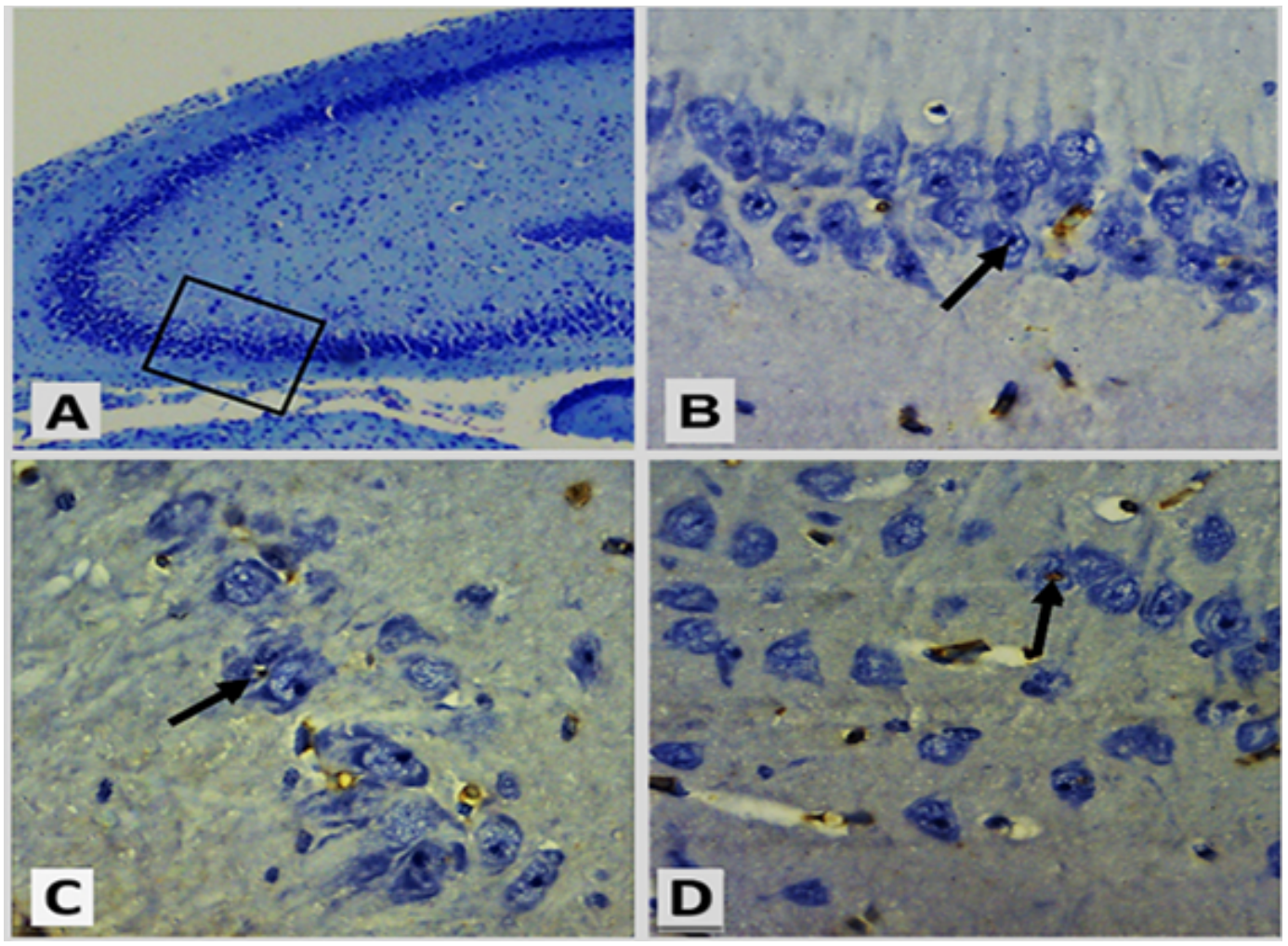

Figure I: Immunohistochemical Bax stained slides from CA3 area of hippocampus in 22 days old pups. The square in slide $A$ indicates the CA3 area and the slides $B, C$ and $D$ are the magnified $C A 3$ areas of respective groups. $B$ : control C/FC group, where the arrow points to a healthy nucleus. C: First generation PTU treated group P/FC where the arrow points to a Bax stained pyknotic nucleus. D: Second generation PTU treated group PP/FC, where apart from disturbed arrangement of pyramidal cells, the arrow points to a pyknotic Bax stained nucleus. The damage in $D$ is significantly intense compared to $B$ and $C$ (40x magnification).

lightly stained spherical nucleus without any signs of Bax stain inside the nucleus were termed viable. Neurons with a shrunken or fragmented nucleus with visible Bax staining were termed apoptotic.

IHC stained slides were used for counting both the normal and apoptotic Pyramidal cells in CA3 area of hippocampus and Purkinje cells in cerebellar cortex. Counting of the cells was done in all squares of the grid, excluding the lower and left border. The cells were counted randomly in each field chosen at the magnification of $100 \mathrm{X}$ and the mean was calculated using SPSS version 21 .

One-way analysis of variance (ANOVA) was used for group comparisons. Pvalue $\leq 0.05$ was considered as statistically significant. Mean \pm SD was calculated for numeric variables (i.e. brain weight of pups, serum levels of $T_{3}$,
$\mathrm{T}_{4}, \mathrm{TSH}$, cell count of Purkinje and Pyramidal cells) and one-way ANOVA was used for calculating the significance of the number of Pyramidal and Purkinje cells within groups.

\section{RESULTS}

The animals were examined daily to evaluate their health and growth. Pups belonging to group C/FC were active and healthy and there was no morbidity or mortality recorded among them. But the pups belonging to groups P/FC and PP/FC had a 30-50\% mortality recorded. Moreover, they remained listless with decrease in appetite.

Mean TSH levels were $2 \mathrm{l} \pm 3 \mathrm{~g} / \mathrm{dl}$, $23.3 \pm 3.5 \mathrm{~g} / \mathrm{dl}$ and $10 \pm 2.1 \mathrm{~g} / \mathrm{dl}$ in $\mathrm{P} / \mathrm{FC}, \mathrm{PP} / \mathrm{FC}$ and $\mathrm{C} / \mathrm{FC}$ respectively ( $\mathrm{P}$ $0.003)$. Mean $\mathrm{T}_{4}$ was $31.7 \pm \mathrm{l} .2 \mathrm{~g} / \mathrm{dl}$, $30.3 \pm \mathrm{l} .3 \mathrm{~g} / \mathrm{dl}$ and $36.3 \pm 0.9 \mathrm{~g} / \mathrm{dl}$ in $\mathrm{P} / \mathrm{FC}, \mathrm{PP} / \mathrm{FC}$ and $\mathrm{C} / \mathrm{FC}$ respectively ( $\mathrm{P}$ 0.030) [Table I].
Mean brain weights was $1.21 \pm 0.21 \mathrm{mg}$, $1.20 \pm 0.41 \mathrm{mg}$ in P/FC and PP/FC groups respectively as compared to I.42 $\pm 0.01 \mathrm{mg}$ in $C / F C$ group ( $p>0.05)$.

Light microscopic examination of IHC stained slides showed disturbed movement of Pyramidal cells in CA3 area of hippocampus in both $\mathrm{P} / \mathrm{FC}$ (Figure I C) and PP/FC (Figure I D) groups, with apoptotic changes observed in their nuclei when compared to $C / F C$ group (Figure I B). In case of Purkinje cells of cerebellar cortex, viable neurons observed in C/FC group had lightly stained spherical nuclei (Figure 2 $B)$, whereas apoptotic neurons in P/FC and PP/FC groups showed shrunken and fragmented nuclei (Figure 2 C and D)

The count of normal Pyramidal cells in CA3 region of Hippocampus was $39.7 \pm 1.24$ in $P / F C$ and $(38.0 \pm 2.62)$ in $\mathrm{PP} / \mathrm{FC}$ groups as compared to $44.7 \pm 2.49$ in $C / F C$ group $(P<0.05)$. On 

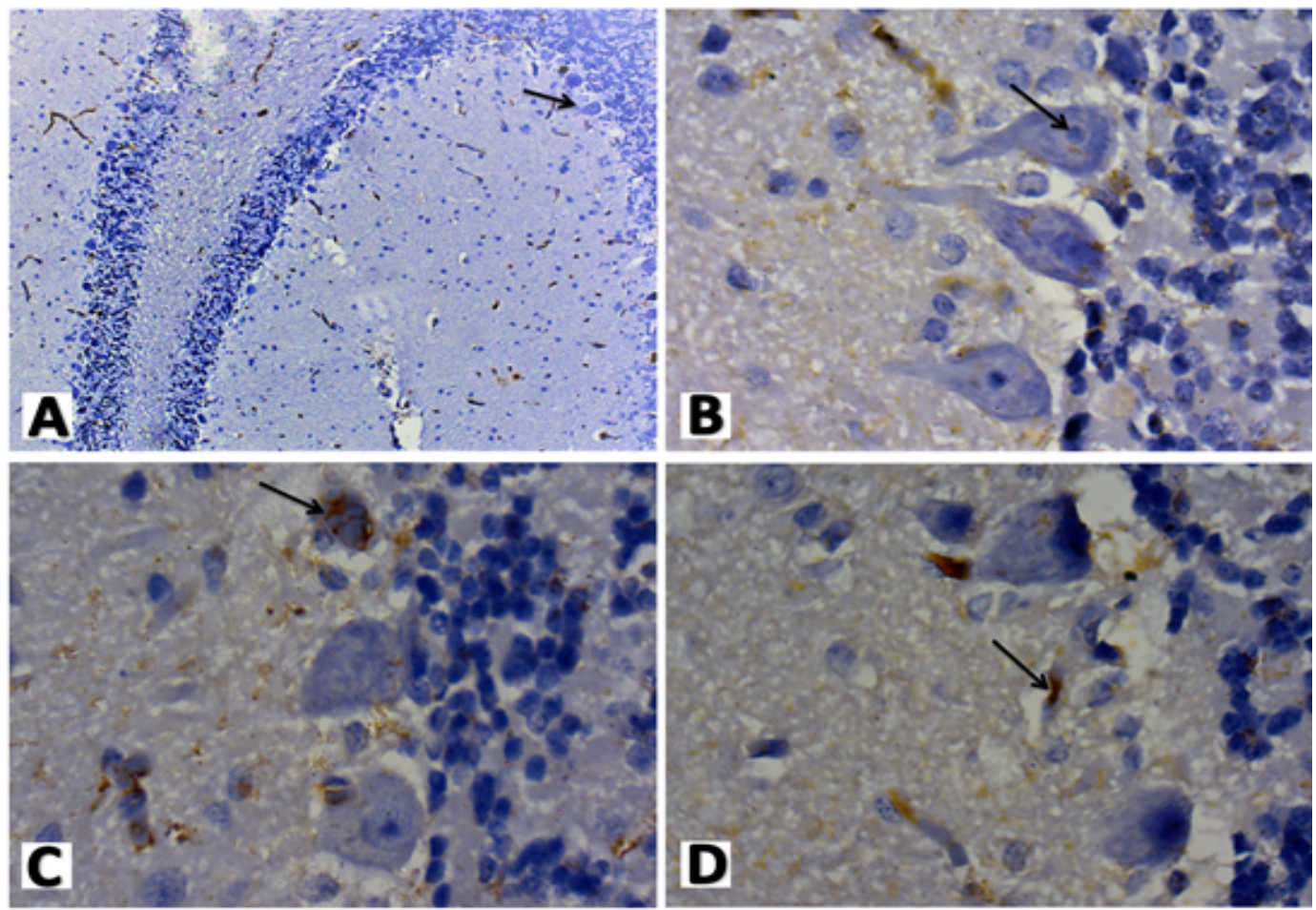

Figure 2: Features observed under immunohistochemical Bax stained slides of Purkinje neurons of cerebellar cortex. Slide A represents the 3 layers of the cerebellar cortex and the arrows point to the middle Purkinje cell layer (I0x magnification). Slide B represents the control group C/FC and the arrow points to a healthy Purkinje cell (100x magnification). Slide $C$ represents the magnified image of first generation PTU treated group P/FC (100x magnification), in which the arrow points to a damaged Purkinje cell with irregular outline. Slide D represents second generation PTU treated group PP/FC, where the arrow points to a shrunken pyknotic Bax stained nucleus of Purkinje cell (I00x magnification)

the contrary, the count of apoptotic Pyramidal cells was $2.7 \pm 0.94$ in P/FC group and $3.7 \pm 0.36$ in $P P / F C$ as compared to $2.0 \pm 0.8 \mathrm{I}$ in $\mathrm{C} / \mathrm{FC}$ group $((P<0.05)$ [Figure 3].

Similar results were seen in Purkinje cells of cerebellar cortex, where the count normal cells was $10.3 \pm 1.24$ and $9.2 \pm 1.36$ in P/FC and PP/FC groups as compared to I $2.2 \pm 1.63$ in C/FC group $(p<0.05)$. On the contrary, the mean count of apoptotic Purkinje cells was $2.7 \pm 0.94$ in first generation (P/FC group) and $3.7 \pm 0.36$ in second generation (PP/FC group) propylthiouracil groups as compared to $\mathrm{I} .3 \pm 0.47$ in control group $(\mathrm{C} / \mathrm{FC}$ group $)(P<0.05)$ [Figure 4].

\section{DISCUSSION}

Metabolic inefficiency created due to THs deficiency during intrauterine life alters neuronal function in the developing rat brain, but how it leads to decline in the functions of neurons later is not well understood. THs play an essential role in many processes that lead to brain development and maturation and their deficiency during intrauterine life can have deleterious consequences on the brain of the developing fetus. ${ }^{4}$ THs have a strong influence on the movement of cells in the hippocampus and cerebellum and even their minor deficiencies are associated with migration defects. ${ }^{3,4}$ For instance, it was observed in a study that maternal hypothyroidism between embryonic days 12 to 15 significantly misplaced cells in the neocortex and hippocampus of the offspring when analyzed at 40 days of age, and the effects of maternal hypothyroidism on the anatomy of the cortex and hippocampus were prominent. ${ }^{20}$ Likewise, in the present study, the movement of Pyramidal cells during neurogenesis was disturbed in $\mathrm{CA} 3$ region of hippocampus of $\mathrm{P} / \mathrm{FC}$ group
(Figure IC), when compared with control group. However, when group $\mathrm{P} / \mathrm{FC}$ was compared to group PP/FC, it was observed that the migration of cells was further affected (Figure ID). This led to the conclusion that the longer the mother is exposed to hypothyroid state, the more serious consequences occur in the newborn and lactating pups.

The hippocampus is extremely sensitive to the changes in the levels of THs during the first month of life in rats and $\mathrm{TH}$ receptors are present in the neurons of hippocampus. ${ }^{4}$ It is stated that hypothyroidism during the neonatal period in rats reduces the dentate granule cells and retards the growth of pyramidal cells in CA3 region of hippocampus. ${ }^{21}$ Since it was previously reported that the number of granule cells of the dentate gyrus is reduced in hypothyroid animals, ${ }^{22}$ therefore, in the present experiment, it was decided to extend this observation to the pyramidal cells of the 


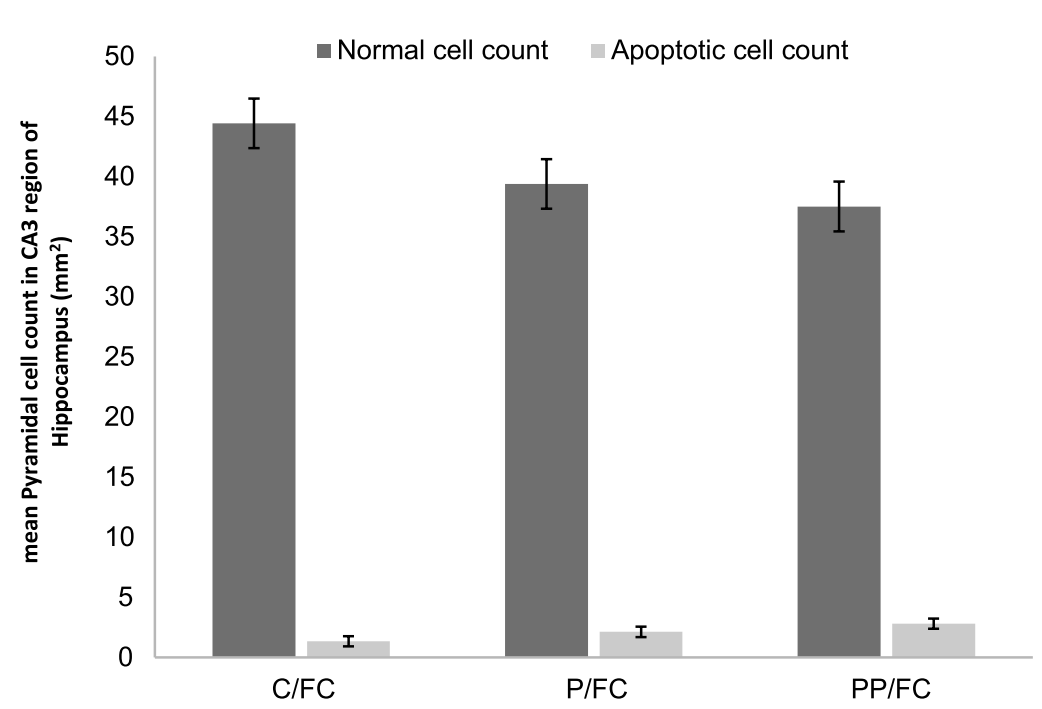

Figure 3: Effects of PTU on the count of pyramidal cells in CA3 area of hippocampus in first and second generation 22 days old pups. The data is expressed as mean $\pm S D(n=9)$. C/FC: control, P/FC: First generation PTU treated group, PP/FC: Second generation PTU treated group.

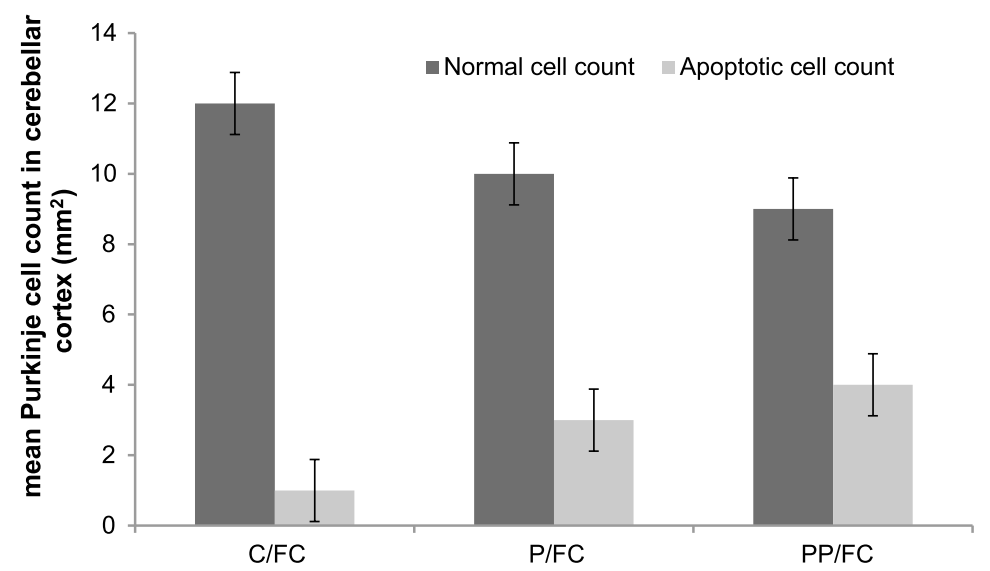

Figure 4: Effects of propylthiouracil (PTU) on the count of Purkinje cells in cerebellar cortex of first and second generation 22 days old pups. The data is expressed as mean \pm SD $(n=9)$. C/FC: control, P/FC: First generation PTU treated pups, PP/FC: Second generation PTU treated pups.

hippocampus, in order to gain further insight into the effects of hypothyroidism on motor neurons in this region of the brain.

In the CA3 region, it was found that after 22 days of birth, there was a reduction in the number of normal Pyramidal cells and a parallel increase in the apoptotic cells, without significantly interfering with the total number of Pyramidal cells in P/FC and PP/FC groups (Figure 3) when compared to C/FC. Microscopic study revealed shrunken and pyknotic Pyramidal cells in CA3 area of hippocampus in P/FC and PP/FC groups (Figure IC and D). This change was either due to degeneration or apoptosis and an increase in the levels of oxidative stress might have been responsible for these alterations. On the other hand, microscopic examination of slides belonging to C/FC group had no signs of apoptosis, as the architecture of the pyramidal neurons was well preserved (Figure IB).

It has been known for decades that cerebellar development is regulated by THs. ${ }^{23}$ The development of cerebellum is fundamentally during the first month of life in rodents. Morphological changes in the brain tissue due to deficiency of THs have been observed in rodents during the neonatal period, and these changes are very similar to the changes observed in humans under similar conditions. ${ }^{24}$ In case of Purkinje cells observed in the current study, viable neurons had lightly stained spherical nuclei (Figure 2B), whereas apoptotic neurons showed shrunken and fragmented nuclei, clearly visible in P/FC and PP/FC groups (Figure 2C and D). A significant decrease was seen in normal cell count of Purkinje cells in P/FC and PP/FC groups compared to control (Figure 4), and in case of apoptotic cells count, PTU treated groups P/FC and PP/FC, had a higher count as compared to control (Figure 4).

In the present study, there was an insignificant reduction in brain weight of hypothyroid pups as compared to the control. Similar to these findings, there was a study conducted by Schwartz et al., in 1997, ${ }^{25}$ in which no significant decrease was reported in the brains of 2 I days old fetuses taken out from hypothyroid rats. In the second generation PP/FC group, the weights of hypothyroid brains were slightly reduced compared to the control. This slight reduction in brain weight indicates that when the mother is exposed to impaired levels of THs, be it for a brief period or a longer period, the fetal and neonatal brain is liable to suffer loss.

The thyroid gland of the fetus does not start THs synthesis until during middle of gestation in humans, and if the mother is hypothyroid before this time period, it has adverse consequences on the development of nervous system of the developing fetus." There was a significant increase in TSH levels in both first and second generation hypothyroid pups showed how due to maternal insufficiency of thyroid hormones, the pups could not compensate for the loss (Table I), as indicated by a rise in the serum levels of TSH and a significant decrease in the serum levels of $T_{4}$. In the present study, with the results of all the parameters combined, including 
histological, morphometric, enzymatic analysis of $\mathrm{T}_{3}, \mathrm{~T}_{4}$ and TSH, it is stated that maternal hypothyroidism during gestation and lactation can have serious consequences on the structure of motor neurons of neonate brain.

Further research is required for better understanding of the effect of maternal low TH levels on fetal brain development and function to devise optimum management strategies for this disorder.

\section{LIMITATIONS OF STUDY}

The effect of low maternal thyroid levels has been confined to only the motor neurons, specifically the Purkinje and Pyramidal cells of the neonate brain. Staining the sensory neurons and the interneurons too would have further provided strength to the study. Moreover, this study has only been conducted on 22 days old pups, as it was not possible to scoop the brains out as a whole from the skull of newborn pups.

\section{CONCLUSION}

The present study concludes that maternal hypothyroidism causes neuronal apoptosis of the neonates in TH deficient brain, which is further aggravated in the second generation pups, if left untreated. This was indicated by structural destruction and apoptosis in the pyramidal neurons of CA3 area in hippocampus along with Purkinje neurons of the cerebellum, more intense in second generation, when compared to the first generation pups.

\section{REFERENCES}

I. Visser TJ. Regulation of Thyroid Function, Synthesis and Function of Thyroid Hormones. In: Vitti P, Hegedus L (eds). Thyroid Diseases. Endocrinology. Springer, 2018. DOI: 10.1007/978-3-319-291956_I-I

2. Cheng S, Leonard JL, Davis PJ. Molecular Aspects of Thyroid Hormone Actions. Endocr Rev 2010;3।(2):139-70. DOI: 10.1210/ er.2009-0007.

3. Ahmed OM, El-Gareib A, El-Bakry A, El-Tawab SA , Ahmed R. Thyroid hormones states and brain development interactions. Int J Dev Neurosci 2008;26(2): 147-209. DOI: 10.1016/j.ijdevneu.2007.09. oll.

4. Roelfsema F, Veldhuis JD. Thyrotropin Secretion Patterns in Health and Disease. Endoc Rev 20I3;34(5):619-57. DOI: 10. 1210/er.2012-1076.

5. Hidayat M, Khaliq S, Khurram A, Lone KP. Protective effects of melatonin on mitochondrial injury and neonatal neuron apoptosis induced by maternal hypothyroidism. Melatonin Res 2019;2(4):42-60. DOI: 10.32794/ $\mathrm{mrl}$ I 250040 .

6. Hidayat M, Haider I, Khurram A, Lone KP. The immunohistochemical localization of Bax in the brain of hypothyroid neonate during maternal melatonin intake. Int J Anat Res 2019;7(3):6901-5. DOI: 10.16965/ijar.2019.259.

7. Ahmed R. Hypothyroidism and brain developmental players. Thyroid Res 2015;8(1):2. DOI: I0.II86/s I3044-0I5-00I3-7.

8. Williams G. Neurodevelopmental and neurophysiological actions of thyroid hormone. J Neuroendocrinol 2008;20(6):78494. DOI: $10.11 \mathrm{II} / \mathrm{j} .1365-2826$. 2008.01733.x.

9. Cicatiello AG, Girolamo DG, Dentice M. Metabolic Effects of the Intracellular Regulation of Thyroid Hormone: Old Players, New Concepts. Front Endocrinol 2018;9:474. DOI: 10.3389/fendo. 2018.00474 .

10. Berbel P, Navarro D, Román GC. An evo-devo approach to thyroid hormones in cerebral and cerebellar cortical development: etiological implications for autism. Front Endocrinol 2014;5: 146. DOI: 10.3389/fendo.2014.00I46.

II. Vega-Nunez E, Alvarez AM, Menendez-Hurtado A, Santos A, Perez-Castillo A. Neuronal mitochondrial morphology and transmembrane potential are severely altered by hypothyroidism during rat brain development. Endocrinology 1997; 138(9):377| 8. DOI: I0.1210/endo.138.9.5407.

12. Miranda A, Sousa N. Maternal hormonal milieu influence on fetal brain development. Brain Behav 20।8;8(2): e 00920 . DOI: 10.1002/brb3.920

13. Preedy VR, Burrow GN, Watson RR. Comprehensive Handbook of lodine; Nutritional, Biochemical, Pathological and Therapeutic Aspects. Elsevier, San Diego, California, USA, 2009. DOI: 10.1016/B978-0-12-374|35-6.X 000I-5.

14. Gharib H, Tuttle RM, Baskin HJ, Fish LH, Singer PA. Subclinical thyroid dysfunction: a joint statement on management from the American Association of Clinical Endocrinologists, the American Thyroid Association, and the Endocrine Society. J Clin Endocrinol Metab 2005;I5(I):24-8. DOI: 10. |2|0/jc.2004-|23|.

15. Singh R, Upadhyay G, Kumar S, Kapoor A. Hypothyroidism alters the expression of $\mathrm{Bcl}-2$ family genes to induce enhanced apoptosis in the developing cerebellum. J Endocrinol 2003; I76(I):39-46. DOI:10.1677/ joe.0.1760039.

16. Bhanja S, Jena S. Modulation of antioxidant enzyme expression by PTU-induced hypothyroidism in cerebral cortex of postnatal rat brain. Neurochem Res 2013; 38(I):42-9. DOI: 10.1007/s I I064$012-0885$.

17. Bernal J. Thyroid hormones and brain development. Vitam Horm 2005;71:95-|22. DOI: 10.1016/ S0083-6729(05)71004-9.

18. Leary SL, Underwood W, Anthony R, Cartner S, Corey D, Grandin T. AVMA guidelines for the euthanasia of animals: 2013 edition. American Veterinary Medical Association Schaumburg, IL.

19. Alzerjawi JM. Effect of propylthiouracil-induced hypothyroidism on reproductive efficiency of adult male rats. Basrah J Vet Res 20 I 3; I2(2): I I 3-2 I. 
20. Zoeller RT. Transplacental thyroxine and fetal brain development. J Clin Inves 2003; III(7):954-7. DOI: I0.II72/JCII8236.

21. Gilbert M. Alterations in synaptic transmission and plasticity in area CAl of adult hippocampus following developmental hypothyroidism. Dev Brain Res 2004; I48(I):II-8. DOI: 10.1016/ j.devbrainres.2003.09.018.

22. Ambrogini P, Cuppini R, Ferri $P$, Mancini $C$. Thyroid hormones affect neurogenesis in the dentate gyrus of adult rat. Neuroendocrinology 2005;8I(4):244-53. DOI: 10.1159/ 000087648.

23. Faustino LC, Ortiga-Carvalho TM. Thyroid hormone role on cerebellar development and maintenance: a perspective based on transgenic mouse models. Front Endocrinol 2014;5:75. DOI: 10.3389/fendo. 2014.00075 .

24. Segni M. Disorders of the Thyroid Gland in Infancy, Childhood and
Adolescence. In: Feingold KR, Anawalt B, Boyce A, Chrousos G de Herder WW, Dungan K, et al., eds. March 18, 2017. Endotext. South Dartmouth (MA): MDText. com, Inc.

25. Schwartz HL, Ross ME, Oppenheimer JH. Lack of effect of thyroid hormone on late fetal rat brain development. Endocrinology 1997;।38(8):3|19-24. DOI: 10. 1210/endo.138.8.5353.

\section{AUTHORS' CONTRIBUTIONS}

Following authors have made substantial contributions to the manuscript as under:

MH: Study design, acquisition, analysis and interpretation of data, drafting the manuscript, final approval of the version to be published

YM: Analysis and interpretation of data, drafting the manuscript, final approval of the version to be published

KPL: Conception and study design, critical review, final approval of the version to be published

Authors agree to be accountable for all aspects of the work in ensuring that questions related to the accuracy or integrity of any part of the work are appropriately investigated and resolved.

\begin{tabular}{|c|}
\hline CONFLICT OF INTEREST \\
Authors declared no conflict of interest \\
GRANT SUPPORT AND FINANCIAL DISCLOSURE \\
NIL
\end{tabular}

\section{DATA SHARING STATEMENT}

The data that support the findings of this study are available from the corresponding author upon reasonable request

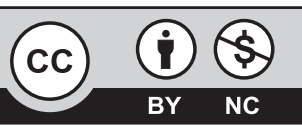

This is an Open Access article distributed under the terms of the Creative Commons Attribution-Non Commercial 2.0 Generic License.

\section{KMUJ web address: www.kmuj.kmu.edu.pk}

Email address: kmuj@kmu.edu.pk 